Ayllón GARCÍA, Jesús Daniel (2019): “La Justicia Restaurativa en España y en otros ordenamientos jurídicos", Ars Boni et Aequi, Año 15, N², pp. 9-29.

\title{
La Justicia Restaurativa en España y en otros ordenamientos jurídicos
}

Restorative Justice in Spain and other legal systems

\author{
Jesús Daniel Ayllón García* \\ Universidad de Cantabria \\ Cantabria, España
}

RESUMEN: La Justicia Restaurativa es una herramienta cambiante que ha tenido diferentes usos dependiendo del Estado en que haya sido empleada para dar solución a conflictos penales. Además, son numerosos los instrumentos al servicio de este modelo de justicia, tales como la mediación penal, las conferencias restaurativas o los círculos de sentencia, los cuales, a su vez, engloban diferentes submodelos restaurativos. Su uso en España, al contrario de lo que sucede en otros países, no ha tenido la aceptación deseada, pese a quedar demostradas las numerosas ventajas que su utilización reportaría, todo ello, se entiende, atendiendo a que el sistema penal español gira en torno a la idea de justicia retributiva y no restaurativa.

PALABRAS CLAVE: justicia restaurativa; mediación penal; círculos de sentencia; programas de reconciliación entre víctima y delincuente.

ABSTRACT: Restorative Justice is a changing tool that has had different uses depending on the State in which it has been used to solve criminal conflicts. In addition, there are many tools at the service of this model of justice, such as criminal mediation, restorative conferences or sentencing circles which, in turn, encompass different restorative submodels. Its use in Spain, contrary to what happens in other countries, has not had the desired acceptance, despite demonstrating the many advantages that this would bring, all this, I understand, taking into account that the Spanish penal system revolves around the idea of retributive justice and non-restorative justice.

KEYWORDS: restorative justice; criminal mediation; sentencing circles; victim offender peconciliation programs.

\section{INTRODUCCIÓN}

Se estudia la Justicia Restaurativa analizando los principales conceptos acuñados por la doctrina española e internacional, sus rasgos definidores y principios en que se asienta, tipo de herramientas en este modelo de justicia y lugares en que se emplean y si este conjunto de instrumentos puede implementarse en el ordenamiento penal español o, al contrario, encuentran obstáculo que impida o dificulte usar estos mecanismos de resolución de conflictos.

\footnotetext{
* Graduado en Derecho por la Universidad de Cantabria, Máster en Fundamentos y Principios del Sistema Jurídico, en Mediación y Gestión de Conflictos, y en Derecho de Familia y Menores por la Universidad de Cantabria, Contratado de Investigación Predoctoral en Universidad de Cantabria, Docente de Grado en Derecho en Universidad de Cantabria. Correo electrónico: ayllonjd@unican.es
} 
El objetivo es proponer la posible instauración de ciertas técnicas de Justicia Restaurativa, como puede ser la mediación penal, y planteo algunas medidas para aplicar esta justicia reparadora en España, abordando antes los inconvenientes provenientes de aquí ser la legislación penal retributiva, y al efecto examino que ha de entenderse por dicha Justicia, sus características, su origen y evolución en diversos países y las principales herramientas a su servicio y, finalmente, los problemas que para su establecimiento presenta el régimen punitivo hispano.

\section{CONCEPTO Y CARACTERÍSTICAS DE LA JUSTICIA RESTAURATIVA}

Entiende DOMINGO DE LA FUENTE que la Justicia Restaurativa es un proceso donde las partes con riesgo en un delito específico resuelven colectivamente cómo tratar las consecuencias del mismo y sus implicaciones para el futuro ${ }^{1}$. Se puede observar que el protagonismo lo tienen las partes en el proceso y no se hace referencia al Estado como garante del ius puniendi, por lo que es posible afirmar que este modelo de justicia dista del tradicional patrón retribucionista propio del ordenamiento jurídico penal español. En palabras de la autora, la Justicia Restaurativa es como un retribucionismo constructivo inverso $^{2}$. Se está ante un movimiento que pretende un cambio de paradigma dentro de los sistemas de justicia penal, superando el actual sistema retributivo ${ }^{3}$.

En la línea recién apuntada, TAMARIT SUMALla sostiene que la Justicia Restaurativa hace referencia a un modelo de justicia contrapuesto al modelo tradicional o retributivo, que enfatiza en reparar el daño causado por un comportamiento delictivo involucrando a las diferentes personas afectadas mediante diversos procesos cooperativos que les hacen interactuar entre ellos ${ }^{4}$.

Para Ríos MARTín la Justicia Reparadora es, en sentido amplio, la filosofía y el procedimiento de resolver los conflictos que tienen en cuenta, principalmente, la protección de la víctima y el restablecimiento de la paz social, mediante el diálogo comunitario y el encuentro personal entre los directamente afectados, con el objeto de satisfacer de modo efectivo las necesidades de todos ellos, devolviéndoles una parte significativa de la disponibilidad sobre el proceso y sus eventuales soluciones, procurando la responsabilización del infractor y la reparación de las heridas personales y sociales provocadas por el delito 5 .

El concepto de Justicia Restaurativa se acuñó oficialmente en el Congreso Internacional de Criminología celebrado en Budapest en $1993^{6}$ y siguió cobrando importancia en los Congresos Internacionales de Victimología celebrados en Australia en 1994 y en Ámsterdam en 1997, así como en el X Congreso de las Naciones Unidas sobre la Prevención del Delito y el Tratamiento del Delincuente 7 .

\footnotetext{
${ }^{1}$ Domingo De La Fuente (2008) p. 6.

2 Domingo De La Fuente (2012) p. 105.

${ }^{3}$ Merino Ortiz y RoMera ANTÓN (1998) p. 287.

${ }^{4}$ TAMARIT Sumalla (2012) p. 62 (similar se expresa el 22/09/2016 Carlos Romera AnTón en Ponencia de Justicia Restaurativa cuando defiende que este término sugiere una respuesta al delito distinta a la pena, comprendiendo la reparación a la víctima, en un sentido flexible, y la reintegración del infractor a través de diversas prácticas de mediación, que tengan en cuenta la comunidad cercana).

${ }^{5}$ Ríos MARTín et al. (2008) pp. 31-32.

${ }^{6}$ VARONA MARTÍNEZ (1998) p.1.

${ }^{7}$ Los participantes convinieron en este Congreso que el concepto de justicia restitutiva debía ser un elemento fundamental de los debates sobre la responsabilidad y equidad respecto de los delincuentes y
} 


\section{AYLLÓN GARCíA, Jesús Daniel (2019): "La Justicia Restaurativa en España y en otros ordenamientos jurídicos", Ars Boni et Aequi, Año 15, N², pp. 9-29.}

El fundamento de este modelo de Justicia se encuentra en la obra de CHRISTIE "Conflicts as Property"8 (1976), en la que manifiesta la necesidad de establecer una alternativa al sistema penal tradicional que permita una solución diferente en relación con los conflictos. No obstante, se considera padre de la justicia restaurativa, por ser el primero en realizar un compendio integral y comprensible del modelo restaurador, a ZEHR, quien concibe la Justicia Restaurativa como un proceso para involucrar, en la medida de lo posible, a aquellos que tienen una participación en un delito específico y para identificar colectivamente y abordar los daños, las necesidades y las obligaciones, para sanar y poner las cosas lo más correcto posible?

Tampoco puede olvidarse el concepto elaborado por MARSHALL, citado muchas veces por la doctrina española e internacional, para quien la Justicia Restaurativa es un proceso de resolución de conflictos mediante el que las partes implicadas en un delito en particular (víctima, ofensor/a y comunidad local) se reúnen para resolver colectivamente la manera de afrontar las consecuencias del ilícito penal y sus implicaciones para el futuro en una relación activa con la Administración de Justicia ${ }^{10}$.

En suma, el concepto de Justicia Restaurativa es evolutivo, cambiante, ha tenido diversas interpretaciones en los países y a su respecto no hay siempre un consenso perfecto y ello por, en parte, las dificultades para traducirlo de manera precisa en los distintos Estados, en los que, a menudo, se usa una gran variedad de términos, por ejemplo, "justicia comunitaria”, "justicia positiva”, "hacer reparaciones”, "justicia relacional", "justicia reparadora", "justicia restitutiva" y "justicia restauradora".

Puede afirmarse que los diferentes conceptos de Justicia Restaurativa giran sobre las premisas de ella ser un medio de solución de conflictos delictivos, siempre intervienen víctima y ofensor, uno y otro además con su red social, y la comunidad o sociedad local del entorno donde se cometió el delito cuando se considere necesario, el proceso lo dirige un tercero -uno o más- facilitador, el objetivo es resolver colectivamente el conflicto para restablecer la paz en la comunidad, reconciliar a las partes y reparar los daños ocasionados, y hay una relación activa con la Administración de Justicia la cual tiene a su cargo controlar la legalidad de la solución adoptada y considerarla a la hora de continuar con el procedimiento.

Para la doctrina, sobre los principales rasgos configuradores de la Justicia Restaurativa

\footnotetext{
las víctimas en el proceso de justicia penal. La intención fundamental de tal justicia era reparar el daño causado y restablecer a delincuente y víctima, en cuanto fuese posible, a su estado anterior a la comisión criminal. Se hizo notar que la culpabilización con fines restitutivos tenía por objeto, primero, avergonzar al infractor para llevarlo a reconocer el perjuicio cometido a la víctima y a la sociedad y, segundo, reincorporar al delincuente en la comunidad y sociedad en su conjunto. La justicia restitutiva ofrecía al proceso de justicia penal una alternativa a las modalidades establecidas de enjuiciamiento y castigo y permitía incorporar a la comunidad y a toda la sociedad en el proceso restitutivo. Se señaló que la justicia restitutiva fue favorablemente acogida en varios países, entre ellos Alemania, Canadá, Cuba, Estados Unidos, Francia, Italia, México, Nueva Zelanda, Polonia, Reino Unido y la República de Corea (Décimo Congreso de las Naciones Unidas sobre Prevención del Delito y Tratamiento del Delincuente, abril 2000, pp. 24-26 [A/CONF.187/15]).

${ }^{8}$ Para mayor detalle vid. CHRISTIE (1992).

${ }^{9}$ ZEHR (1985) p. 16

${ }^{10}$ Marshall (1999) p. 5.
} 
en el ámbito español, es imprescindible tener presente el principio de voluntariedad ${ }^{11} \mathrm{y}$ el resto de principios procesales del sistema de justicia tradicional, esto es, la Justicia Restaurativa debe satisfacer las garantías procesales pero, tal como sucede en la Justicia penal de menores, los principios del proceso sufren ciertas modulaciones, sobre todo el principio de legalidad que ha de estar complementado con el de oportunidad; la Justicia Restaurativa es un medio de resolución de conflictos complementario al sistema judicial $^{12}$ y no alternativo pues en este último caso se vulneraría el principio de legalidad ${ }^{13}$ recogido en el art. 25 de la Carta Española ${ }^{14}$; ha de darse solución o respuesta flexible a los acontecimientos producto de la comisión del delito, a la víctima y al delincuente, considerando cada caso individualmente y por ende la Justicia Restaurativa supone una opción por el diálogo y no por la confrontación ${ }^{15}$; el delito es una violación o infracción de las personas y de las relaciones interpersonales, un conflicto entre individuos que desemboca en ofensas a la víctima, la comunidad y el ofensor y, en segunda instancia, es una violación contra el Estado porque las víctimas y la sociedad se han visto dañadas y han de ser restauradas ${ }^{16}$; las infracciones dan lugar a obligaciones y responsabilidad y el deber de quien delinque es hacer las cosas de la mejor manera posible para reparar el daño causado y el de la comunidad es para con las víctimas y los delincuentes y bienestar general de sus miembros ${ }^{17}$; se intenta con este sistema fortalecer la comunidad para evitar futuros perjuicios, y en los círculos y las conferencias restaurativas, como incluyen a los indirectamente afectados, se fortalece el tejido social y las relaciones de las personas entre si $^{18}$; el infractor tiene que reconocer los elementos fácticos básicos del caso ${ }^{19}$ y aceptar su responsabilidad ya que la justicia restaurativa busca curar y reparar los errores: se maximizan las oportunidades de intercambio de información, participación, diálogo y consentimiento mutuo entre la víctima y el delincuente ${ }^{20}$; $y$, la reparación no se circunscribe exclusivamente a responder civilmente a las víctimas (factor económico) porque el papel psicológico y personal (factor intra e interpersonal) también juega un rol muy importante.

La Justicia Restaurativa y su elemento esencial reparación han de situarse en el seno del Derecho Penal pues necesita de este para decidir qué es delito y quién es víctima y autor $^{21}$ porque el principio de legalidad exige que la conducta que constituye la contravención esté expresamente recogida en la ley (nullum crime sine lege) ${ }^{22}$. Se entiende que es un método que está dirigido a las causas subyacentes del conflicto ${ }^{23}$.

${ }^{11}$ TAMARIT Sumalla (2013) p. 142.

${ }^{12}$ Ibíd.

${ }^{13}$ Para profundizar sobre el principio de legalidad en el sistema penal español vid. CARBOnELL MATEU (1995) pp. 102-116.

${ }^{14}$ En esta misma línea se expresaba Consejo Económico y Social de Naciones Unidas al afirmar que las prácticas de justicia restaurativa debían considerarse como complemento de los sistemas de justicia establecidos y no como un mecanismo destinado a reemplazarlos (Resolución E/CN.15/2002/5/Add.1 Comisión de Prevención del Delito y Justicia Penal, $11^{\circ}$ período sesiones, Viena, 16 a 25 de abril de 2002, Temas 3 y 4 del programa provisional, Debate temático sobre la reforma del sistema de justicia penal: logro de la eficacia y la equidad Reglas y normas de las Naciones Unidas en materia de prevención del delito y justicia penal, p. 6).

${ }^{15}$ Ríos Martín y Olalde Altarejos (2011) p. 13.

${ }^{16}$ ZEHR y GOHAR (2005) pp. 82-83.

${ }^{17}$ ZEHR y GOHAR (2005) pp. 83-84.

${ }^{18}$ Domingo De La FuENTE (2012) p.112.

${ }^{19}$ TAMARIT SUMALla (2013) p.158.

${ }^{20}$ ZEHR y GOHAR (2005) pp. 85-87.

${ }^{21}$ FerReirós MARCOS et al. (2011) pp. 78-79.

${ }^{22}$ Señala MiR PUIG (2003) p. 12 que aunque "derecho penal" expresa la necesidad de las penas hallarse previstas por la ley (por el derecho) y "derecho criminal" da idea de no ser delito (crimen) lo que no esté 
Dichas las principales características de la Justicia Restaurativa, señalo que ella es incipiente en España y depende de adquirir importancia en su sociedad y cultura jurídica aunque para esto sería conveniente que la comunidad deje de sentirse identificada con la que Ihering plasmaba en su obra La Lucha por el Derecho (1881) como una en la que el ser humano litiga constantemente e incluso en ocasiones en las que aún ganando un pleito el resultado es poco deseable para el vencedor porque el ansia de que un Juez le dé la razón lo compensa el sacrificio económico de tener que sufragar costas del juicio.

\section{ORIGEN Y EVOLUCIÓN DE LA JUSTICIA RESTAURATIVA}

El concepto de Justicia Restaurativa se funda en tradiciones indígenas de Australia, Nueva Zelanda, Estados Unidos y Canadá, en donde se han realizado ciertas prácticas de Justicia Restaurativa basadas en la reparación del daño y la sanación de las heridas ${ }^{24}$ a través de la discusión y la interacción entre víctima e infractor y, a veces, con la comunidad en la que moran.

En el siglo pasado, a partir de la década de los cincuenta empieza a llamar la atención este proceso de desposesión del conflicto al que se sometió a las víctimas y lo que ello conllevaba $^{25}$ y se comenzó a tener conciencia que el trance, antes que del Estado, es del afectado y del victimario, propugnándose entonces nuevas soluciones paliativas a esa situación de marginación abogándose activamente por crear nuevos espacios de participación de la víctima en los mecanismos de resolución de un conflicto del que es parte determinante ${ }^{26}$.

La mayoría de los autores entiende que este modelo de Justicia se generó en Norteamérica en la década de los setenta ${ }^{27}$ y el primer caso es de 1974 en Kitchener, Ontario (Canadá), donde un Tribunal justamente ordenó una sentencia de Justicia Restaurativa. El conflicto delictivo fue que dos jóvenes menores de edad son detenidos por actos vandálicos (daños a 22 propiedades de un barrio) y un funcionario de libertad condicional convenció al Juez para que, tras dictar sentencia, propusiese que los muchachos se reunieran con todas las víctimas y aconteció que el magistrado, luego de los encuentros, determinó a los infractores restituir a los afectados como condición para la libertad condicional y el éxito que esto tuvo propició crear el primero de muchos Programas de Reconciliación entre Víctima y Delincuente (Victim Offender Reconciliation Programs), conocidos bajo las siglas VORP, liderado por Mark Yantzi. Este programa lo apoyó del Comité Central Menonita y colaboró el departamento local

descrito como tal por el derecho, cada una de estas designaciones apunta a uno de los extremos de la fórmula "nullum crimen,nulla poena sine lege", sin que pueda decirse que una es más fiel a ella que la otra.

${ }^{23}$ Hombrado Trenado (2015) pp. 4-5.

${ }^{24}$ Así en Conclusiones del I Congreso Internacional sobre Justicia Restaurativa y Mediación Penal, celebrado en Burgos, España, el 4 y 5 de marzo de 2010 (disponible en: http://www.justiciarestaurativa.org/news/conclusiones\%20congreso\%20marzo\%202010.pdf/view, fecha de consulta: 27 de marzo de 2019).

${ }^{25}$ Vid. FerReirós MARCOS et al. (2011) pp. 78-79.

${ }^{26}$ GARCÍA FERNÁNDEZ (2014) p. 15.

${ }^{27}$ En este sentido, se pueden consultar PÉrez SANZBERro (1999) pp. 15-16, LóPEZ RuANOva (2010) p. 262, Mccold (2013) p. 9, MERino Ortiz y Romera ANTÓn (1998) p. 286, GARcía Fernández (2014) p. 15, Romera ANTón (2007) p. 191, Domingo De La Fuente (2008) p. 5 y Ferreirós Marcos et al. (2011) p. 1. 
de probation $^{28}$ y el segundo se inició también con ayuda Menonita en Indiana y en 1982 otros dos VORP se establecieron en British Columbia y en California. Junto a los VORP surgieron a comienzos de la década de 1980 en Estados Unidos los programas de "Mediación Víctima-Ofensor" (Victim Offender Mediation), conocidos con las siglas VOM, como una segunda oleada de prácticas explícitas de mediación restaurativa ${ }^{29}$, impulsados también por miembros de la comunidad menonita.

En el continente europeo en 1977 el primer programa de Justicia Restaurativa se da en Gran Bretaña con el nombre de Victim Offender Reparation y es el reflejo de lo que hoy en el ámbito de los menores se conoce como los Youth Offender Team (YOT) y los Youth Justice Panels (Paneles de Justicia Juvenil) en Gran Bretaña ${ }^{30}$. Posteriormente se organizaron los Comités noruegos de resolución de conflictos y tienen lugar las primeras experiencias municipales en Finlandia, y a mediados de la década de los ochenta se dan los primeros pasos hacia la Justicia Restaurativa en Holanda, Alemania y Austria, y a inicios de la década de los noventa se emprenden estas experiencias en Francia, Italia, Bélgica y España. De este modo, se extiende rápidamente el modelo reparador en Europa pero hay que destacar que en la Justicia juvenil es donde ha encontrado especial aplicación porque la legislación en esta materia es más flexible y permite a los jueces mayor discrecionalidad ${ }^{31}$. En España, con las últimas reformas en lo penal, se ha otorgado, si bien tímidamente, carta de naturaleza a las prácticas de Justicia Restaurativa.

Hay sí territorios no conformes con los VORP y el paradigma restaurativo y muestran más interés por las Conferencias de Grupos Familiares (CGF) como modelo restaurativo de resolución de conflictos y en Nueva Zelanda este sistema se institucionaliza en 1989 con la Ley de Justicia Juvenil combinando elementos de justicia (grado de culpabilidad) y de bienestar social (paternalismo y proteccionismo), en Australia destaca la modalidad de CGF elaborada por el departamento de policía de Wagga en 1991 basada en la "vergüenza reintegradora" (reintegrative shaming) ${ }^{32}$.

Por último, está el modelo de los Círculos Restaurativos que son un intento de retomar el sistema tradicional aborigen en Norte América, cuyo primer reconocimiento se sitúa en el desierto del suroeste de los Estados Unidos, con la población aborigen Navajo en $1982^{33}$.

Se deduce que la Justicia Restaurativa aparece en la década de 1970 en Canadá y solo en el s. XXI empieza a implementarse en España pero, vistas las posibles ventajas que este sistema podría ofrecer, modestamente y con logro menor del deseado.

\section{HERRAMIENTAS DE JUSTICIA RESTAURATIVA}

Para SOLETO MuÑoz son varios los instrumentos al servicio de la Justicia Reparadora en función de cómo interaccione el sistema penal de cada Estado con los instrumentos

\footnotetext{
${ }^{28}$ Es una alternativa a la pena de prisión en la cual, en vez de estar encarcelado, se está a prueba y, bajo determinadas condiciones, en libertad supervisada.

${ }^{29}$ McCOLD (2013) p. 11.

${ }^{30}$ Para profundizar más en la cuestión vid. WERTH WAINER (2005) pp. 111 y ss.

${ }^{31}$ LÓPEZ RuANOVA (2010) p. 262.

32 Merino OrTiz y RomerA ANTÓN (1998) pp. 290-291.

${ }^{33}$ MCCOLD (2013) p. 16.
} 


\section{AYLLÓN GARCíA, Jesús Daniel (2019): “La Justicia Restaurativa en España y en otros} ordenamientos jurídicos", Ars Boni et Aequi, Año 15, N², pp. 9-29.

propios de ella ${ }^{34} \mathrm{y}$, según afirma MCCOLD, las herramientas de Justicia Restaurativa son la mediación penal, las conferencias restaurativas y los círculos restaurativos ${ }^{35}$, tres categorías dentro de las que destacan diferentes submodelos que en ellas tienen cabida.

\section{Mediación penal}

En un primer momento mediación penal era Justicia Restaurativa y esta tal mediación, y un tercero neutral (generalmente voluntario de la comunidad entrenado o especialista en trabajo social) facilitaba el diálogo entre víctima y ofensor, quienes hablaban acerca de cómo el crimen les afectó, compartían información, desarrollaban por escrito un acuerdo de restitución mutuamente satisfactorio y con un plan de seguimiento ${ }^{36}$, después la Justicia Restaurativa evolucionó hacia tres modelos generales, esto es, la mediación víctima-ofensor (VOM), basada en el trabajo social, los programas de reconciliación, que se fundan en la buena fe entre el ofensor y la víctima (VORP), y la mediación comunitaria, basada en la legalidad.

\section{A) MEDIACIÓN VÍCTIMA-OFENSOR (VOM) Y PROGRAMAS DE RECONCILIACIÓN ENTRE VÍCTIMA-OFENSOR (VORP).}

La VOM y los VORP son modelos implementados muy modestamente en España (y en la mayoría de los Estados europeos) bajo el nombre de lo que la doctrina denomina mediación penal ${ }^{37}$. La VOM se orienta sobre todo al diálogo, enfatizando menos en la reconciliación y más en la sanación de la víctima, en la responsabilidad del infractor y en la restauración de las pérdidas ${ }^{38}$. Los VORP dan prioridad a reconciliarse víctima y delincuente, lo que es sumamente conveniente si ellos deben seguir relacionándose, cual puede acontecer si son vecinos o parientes. También este modelo se conoce con el nombre de Face-to-face mediation y lo importante es la voluntad de víctima e infractor de tomar parte en el procedimiento, el que se caracteriza por no haber presencia judicial y dirigirlo un mediador experto o un facilitador ${ }^{39}$.

Este modelo de mediación penal se instaura timorato en España porque, en términos estrictamente legales y en cuanto a la responsabilidad penal de adultos, se vive en un clima de alegalidad, además de contravenirse el principio de legalidad.

\section{B) MEDIACIÓN COMUNITARIA}

La mediación penal comunitaria, que aparece vinculada a los orígenes del instituto de la mediación $^{40}$, devuelve a la comunidad la situación de conflicto que se originó en ella, cobrando especial atención no únicamente la reparación del daño sino también el

\footnotetext{
${ }^{34}$ Vid. SOlETo MuÑOz (2013) pp. 83 y ss.

${ }^{35}$ MCCOLD (2013) p. 10.

${ }^{36}$ MCCOLD (2013) p. 11.

${ }^{37}$ Vid. GARCía FERNÁNDEZ (2014) pp. 3-5.

${ }^{38}$ MCCOLD (2013) p. 16 y GARCÍA FERNÁNDEZ (2014) p. 5.

${ }^{39}$ BARONA VILAR (1999). p. 146.

${ }^{40}$ Según McCOLD (2013) p.11 la mediación comunitaria en los Estados Unidos fue el movimiento de primera generación (de justicia restaurativa) a comienzos de la década de 1970.
} 
fortalecimiento de los vínculos y la restauración de la convivencia, tanto en lo que podría ser su contexto inmediato (el instituto) como a nivel ciudadano ${ }^{41}$.

La mediación penal comunitaria se caracteriza por ser Política, porque, a través del ejercicio de la ciudadanía democrática y la participación en la búsqueda del bien común y la realización de la justicia, persigue minimizar la violencia estatal, resolver pacíficamente y con diálogo los conflictos en todos los órdenes de la sociedad, Comunitaria, pues pretende -entre otros- devolver el protagonismo a la sociedad civil, generar tejido social, Dialógica, porque reduce lo dialéctico al momento de la comisión del delito y reconduce el resto del iter por la vía dialógica, Veraz, pues busca la verdad material por encima de los formalismos, Reparadora en múltiples direcciones, porque la víctima encuentra una reparación patrimonial, simbólica, afectiva o explicativa del daño sufrido, el infractor ve atendido el daño personal que está en la base de la dinámica delincuencial y la comunidad sale reforzada y reparada en tanto todo delito quebranta la paz social, y Responsabilizadora, pues primariamente hace responsable al ofensor y le ayuda a empatizar y ponerse en el lugar del otro ${ }^{42}$.

En suma, la mediación comunitaria supone una mayor identificación con el proceso y una mayor motivación para participar en él.

\section{Conferencias restaurativas}

Las conferencias restaurativas (conferencing) involucran a todos los interesados directos en el conflicto en determinar la mejor manera de reparar el daño producido por la conducta delictiva. Los modelos varían de acuerdo con la participación que tiene la víctima, los que la apoyan y los defensores del infractor, incluyendo los miembros de la familia y a otras personas relevantes, y también en función de quién es el facilitador y que puede ser el grupo entero o una junta familiar que negocia los resultados y aprueba los acuerdos ${ }^{43}$. La inclusión de la comunidad en el proceso de diálogo y decisión hace que aquella deje de ser un ente abstracto y asuma protagonismo ofreciendo apoyo a la víctima y al ofensor, implicándose en la superación del conflicto.

El conferencing es la forma que mayor interés puede suscitar, habida cuenta de su dimensión intensamente restaurativa y que se extiende en otros países que España, y esta práctica en Nueva Zelanda se inició en 1989 con la Childen, Young Persons and Their Families Act y su finalidad es involucrar a todas las personas afectadas por el delito en la decisión sobre el modo de darle respuesta ${ }^{44}$.

Las conferencias restaurativas normalmente terminan con una ceremonia de perdón y arrepentimiento, que significan reintegrar al individuo en su comunidad, y la amenaza de perder el estatus relacional es real y no puede hacerla Estado sino aquellos que tienen relación directa con la persona a quien cuestionan su comportamiento ${ }^{45}$ (familia, víctima, comunidad en general, etc.).

Hay cuatro principales modelos de conferencias restaurativas y son los siguientes:

\footnotetext{
${ }^{41}$ Almirall SERRA et al. (2011) pp. 175-176.

${ }^{42}$ Segovia Bernabé (2010) pp. 35-65.

${ }^{43}$ McCOLd (2013) p. 19.

${ }^{44}$ TAMARIT Sumalla (2013) p. 147.

${ }^{45}$ RoMERA ANTÓN (2007) p. 199.
} 


\section{A) CONFERENCIAS DE GRUPO FAMILIAR O COMUNITARIAS}

Para la mayoría de la doctrina las conferencias de grupo familiar y las comunitarias son una misma herramienta dentro de las conferencias restaurativas y es una de las primeras prácticas restauradoras implementadas institucionalmente ${ }^{46}$, Son una experiencia de origen neozelandés basado en el sistema tradicional de resolución de conflictos de los maorís en caso de ser el victimario una persona joven. Como en los procesos de mediación, hay ayuda de un facilitador y la principal idea de este modelo es que el grupo, formado por la comunidad, amigos, familiares, victimario y víctima, responde, o sea, todos son responsables de encontrar una solución adecuada al conflicto creado ${ }^{47}$, dirigiendo a los principales implicados (víctima y ofensor) para encontrar un consenso. La mayoría de los casos los dirige la policía a través de "precaución restaurativa" y también mediante conferencias de grupos de cortes familiares. Este modelo ampliamente se emplea por la policía del Sur de Australia, Sudáfrica, Irlanda, Lesoto, y se aplica en las ciudades de Minnesota, Pennsylvania y Montana ${ }^{48}$.

Las conferencias comunitarias a menudo se usan como un programa de medidas alternativas a las que el delincuente puede ser remitido desde el sistema de justicia penal y el grupo comunitario al que es enviado el infractor monitoriza que él cumpla los términos del acuerdo.

Este modelo difiere del de mediación porque junto con las víctimas primarias del delito incluye a las secundarias y los miembros son invitados a participar en el proceso, se les escucha y tiene en cuenta, lo que implica considerar otros puntos de vista sobre cómo afecta la infracción penal pues no es un hecho aislado ya que acontece dentro de una comunidad.

El propósito no es humillar a quien delinque sino que entra en juego la vergüenza reintegrativa, esto es, la sociedad denuncia como inaceptable la conducta del transgresor pero reafirma su compromiso de que si él quiere cambiar lo van a apoyar para reintegrarle socialmente ${ }^{49}$.

\section{B) TOMA DE DECISIONES DENTRO DEL GRUPO FAMILIAR}

El modelo de toma de decisiones dentro del grupo familiar o Family group decision making se originó en Canadá (1994) como respuesta a contextos de violencia familiar de manera más amplia que el simple cuidado y protección de un niño y su principio rector es que esa violencia requiere que intervengan las autoridades competentes y que las mejores soluciones de largo alcance permiten a las partes afectadas elaborar un plan adaptado a su situación familiar y cultural concreta ${ }^{50}$. Este modelo hace uso de la teoría del trabajo efectivo que ayuda a aclarar el contexto estructural en el que se produce la

\footnotetext{
46 Otros autores, por ejemplo McCOLD (2013) p. 23, las estudian por separado, y opinan que las Conferencias Comunitarias, también conocidas como conferencias de Real Justice, son una evolución del modelo Wagga Wagga que más adelante tendré la oportunidad de analizar.

${ }^{47}$ Hombrado TRENAdo (2015) p. 8.

48 Así Naciones Unidas, Oficina contra la Droga y el Delito en Manual sobre Programas de justicia restaurativa (2006) p. 20.

${ }^{49}$ Domingo De La FuenTe (2012) p. 109.

${ }^{50}$ MCCOLD (2013) p. 21.
} 
confrontación reintegrativa y cómo este proceso de empoderamiento se extiende en torno a la responsabilidad de cuidar ${ }^{51}$.

\section{C) UNIDAD DE REUNIÓN FAMILIAR}

En los Family Unity Meeting los trabajadores sociales profesionales y la familia extensa colaboran para planificar el cuidado y la protección de los miembros de la familia, siendo los padres quienes deciden, por medio de un veto, los integrantes de la familia que serán invitados y los profesionales que permanecerán con aquella durante el proceso $^{52}$. Este modelo ha sido probado en varios lugares de Estados Unidos antes de que el de Conferencias de Grupos Familiares fuera ampliamente conocido ${ }^{53}$.

\section{D) CONFERENCIA POLICIAL}

Dentro de los modelos de conferencias restaurativas, el desarrollado por el Departamento de Policía de Wagga Wagga es el que más difusión internacional ha tenido, y en este tipo las conferencias las realizan oficiales de policía uniformados o personal escolar ${ }^{54}$. Esta herramienta restaurativa fue promovida por Terry O'Conell, quien la introdujo como técnica policial en $1991^{55}$ y en un principio este patrón se limitó a delitos menores y se expandió progresivamente a otras áreas, aplicándose en la actualidad a jóvenes-adultos y menores infractores de una amplia gama de ilícitos penales contra la propiedad y de lesiones y si hay varios victimarios no se celebran diversos procedimientos restaurativos sino que la conferencia se hace con todos ellos de forma grupal ${ }^{56}$.

Este sistema se basa en la teoría de John Braithwaite de la vergüenza reintegradora (reintegrative shaming) ${ }^{57}$, que enfatiza ser posible que cambie de comportamiento el joven agresor, y en la que la vergüenza es un elemento necesario para restablecer el daño hecho y evitar que se vuelva a producir y no es estigmatizadora sino que reintegradora ${ }^{58}$.

\section{Círculos restaurativos}

El círculo es fundamental para culturas tradicionales aborígenes y los procesos sociales, y los procedimientos que utilizan círculos para el manejo del delito y del comportamiento delictivo se originan a partir de los conceptos tradicionales de libertad e individualidad - una persona no puede imponer una decisión a otra-. Los modelos de Justicia Restaurativa que emplean círculos evolucionaron siguiendo un paradigma de la sanación (círculos de sanación) para disponer de situaciones y uno de co-enjuiciamiento (círculos de sentencia) que se limita a elevar recomendaciones a la autoridad judicial para la disposición del caso ${ }^{59}$.

\footnotetext{
${ }_{51}^{51}$ Vid. PENNELL y BURFORD (1996) pp. 206-220.

${ }^{52}$ MCCOLD (2013) p. 21.

${ }^{53}$ Ibíd.

${ }_{55}^{54}$ Merino OrTiZ y Romera ANTÓN (1998) p. 290..

${ }_{55}^{55}$ MCCOLD (2013) pp. 22-23.

${ }^{56}$ Merino ORTIZ y ROMERA ANTÓN (1998) p. 290.

${ }^{57}$ Para más información sobre esta teoría vid. LANGON CUÑaRRO (2000) pp. 63-68.

${ }^{58}$ Vid. ROMERA ANTÓN (2007) pp. 196-199.

${ }^{59}$ MCCOLD (2013) p. 16.
} 


\section{A) CÍRCULOS DE CONSTRUCCIÓN DE PAZ}

El círculo es un proceso que reúne a personas que quieren resolver un conflicto, reconstruir sus vínculos, sanar, brindar apoyo, tomar decisiones o realizar otras acciones en las cuales la comunicación honesta, el desarrollo de los vínculos y el fortalecimiento comunitario son parte esencial de los resultados esperados, y las diferentes funciones de los círculos les dan su nombre siendo "círculos de paz" el de uso más genérico y el que se emplea para denominar los círculos para la solución de conflictos ${ }^{60}$.

En 1982 la Región Navajo estableció Tribunales Navajos de Pacificación bajo la dirección del oficial de Justicia Tribal Robert Yazzie. Si una persona se sentía ofendida por otra pedía al agresor que actuase correctamente (nalyeeh) y si esto no funcionaba el perjudicado podía recurrir a un líder respetado de la comunidad para que organizase y facilitase un proceso de paz, donde los miembros de la familia de las víctimas y de su clan y los correspondientes ofensores intentaran llegar a un acuerdo ${ }^{61}$. En enero de 2000 el Consejo de la Región Navajo reformó su Código Penal, eliminó cárcel y multas por 79 delitos, incorporó el concepto tradicional de nalyeeh y requirió el uso de mecanismos de pacificación en los casos penales y que los tribunales velen por el derecho de las víctimas $^{62}$.

Los círculos de paz se utilizan para construir relaciones, promover la paz y las relaciones armoniosas en las comunidades, y también para solucionar problemas $\operatorname{concretos}^{63}$.

\section{B) CÍRCULOS DE SANACIÓN}

El origen de los Círculos de Sanación es de comienzos de la década de 1980 con el Programa de Sanación de Hollow Water en Manitoba como respuesta al incesto y asalto sexual buscando no solo sanar conexiones íntimas y la dignidad humana sino también enfrentar las disposiciones sociales que permiten el florecimiento de la violencia ${ }^{64}$.

Los círculos de sanación fueron creados por líderes tribales locales, principalmente el Ojibwa Women, y Hollow Water sigue utilizando círculos desde 1986 para transformar la disfunción social en su comunidad, un estudio realizado por los Servicios de Consejería nativos de Alberta (2001) confirmaron que su enfoque es una respuesta altamente efectiva, en términos de costo-efectividad, a los delitos sexuales ${ }^{65}$.

El fin principal de estos círculos es apoyar a quien ha sufrido una experiencia dolorosa, se pretende que ella sepa que cuenta con ayuda de la comunidad en general y de personas que podrán ser sus referentes, sirven para que la víctima se desahogue emocionalmente, narre su vivencia, exponga su dolor y se sienta escuchada, pudiendo

\footnotetext{
${ }^{60}$ PRANIS (2012) p. 7.

${ }^{61}$ McCOLD (2013) p. 17.

${ }^{6}$ Ibíd.

${ }^{63}$ PRANIS (2012) p. 12.

${ }^{64}$ MCCOLD (2013) p. 17.

${ }^{65}$ MCCOLD (2013) p. 18.
} 
entonces los que participan en el círculo conocer sus necesidades y ayudarle de una manera más adecuada ${ }^{66}$.

\section{C) CÍRCULOS DE SENTENCIA}

Los círculos de sentencia son un intento de retomar el sistema tradicional aborigen en Norte América, en el que los miembros de una comunidad aconsejan y participan sobre el dictamen de la sentencia en un caso concreto que afecta a otro integrante de esa colectividad $^{67}$. Un círculo de sentencia es un proceso dirigido por la comunidad que se asocia con el sistema de Justicia Penal para consensuar un plan de sentencia, se utiliza un ritual y una estructura de círculo tradicionales para crear un espacio de respeto en el que los miembros comunitarios interesados, las víctimas y ofensores y los defensores de ellos, el juez, el fiscal, la policía y los empleados de los tribunales pueden hablar abiertamente en la búsqueda común de la comprensión del evento ${ }^{68}$, y estas personas, ya formado el círculo, tienen el mismo nivel de poder, si bien la opinión de los ancianosjefes se toma como guía para decidir sobre la conducta del infractor.

El Juez participa con un papel distinto al de su cargo pero una vez alcanzado el consenso de actuación frente al acusado en el círculo ${ }^{69}$ retorna a su rol inicial y se compromete a imponer la sentencia que el círculo ha recomendado ${ }^{70}$.

Las principales características que definen a los círculos de sentencia son promover la curación de todas las partes afectadas, dar oportunidad al infractor de enmendar sus actos, dar a las víctimas, infractores, miembros de las familias de ambos y a la comunidad una voz en el procedimiento y una responsabilidad compartida de hallar resoluciones constructivas, se enfoca en la conducta actual y futura y tiene una visión más amplia del conflicto que la justicia tradicional, ayuda a reconstruir relaciones dentro de comunidades y de familias, y protege a la víctima tratando de que el hecho cause la mínima disfunción en ella y a su familia ${ }^{71}$.

\section{LA JUSTICIA RESTAURATIVA EN EL ORDENAMIENTO JURÍDICO ESPAÑOL}

Ya vista en un plano internacional, se analiza la Justicia Restaurativa desde el punto de vista del Derecho español tratando las cuestiones que son más controvertidas a efectos de implementarla.

Desde ya, el mecanismo de resolución de conflictos de que se trata podría innovar la

\footnotetext{
${ }^{66}$ CHOYA FORÉS (2015) pp. 23-24.

${ }^{67}$ Merino ORTIZ y RoMERA ANTÓN (1998) p. 293.

${ }^{68}$ MCCOLD (2013) pp. 18-19.

${ }^{69}$ MERINO ORTIZ y ROMERA ANTÓN (1998) p. 294.

${ }^{70}$ Este compromiso que adquiere el Juez guarda cierta similitud con el papel que el MagistradoPresidente desempeña en el Tribunal del Jurado español, con la salvedad que, en el Tribunal del Jurado español, el mentado Magistrado únicamente auxilia a los demás miembros del jurado y no participa en la votación sobre los hechos y la culpabilidad mientras que, en los círculos de sentencia, el Juez participa en la mediación, en la elaboración de la decisión judicial y en la determinación de la culpabilidad. Para más información sobre el Tribunal del Jurado Español puede consultarse su Ley Orgánica 5/1995, de 22 de mayo.

${ }^{71}$ Merino Ortiz y Romera Antón (1998) p. 294, Domingo De La Fuente (2008) p. 11 y García FERNÁNDEZ (2014) p. 5.
} 
AYLlón GARCíA, Jesús Daniel (2019): “La Justicia Restaurativa en España y en otros ordenamientos jurídicos", Ars Boni et Aequi, Año 15, N² 2, pp. 9-29.

justicia penal española pero esto ciertamente pugna con el clamor social actual de incrementar las sanciones privativas de libertad y cuyo logro culmine sin duda es la incorporación en el catálogo punitivo de la prisión permanente revisable -art. 33.2a) Código penal, en vigor desde el 1 de julio de 2015-. Es más, no resulta extraño escuchar sobre la necesidad del endurecimiento de las penas ${ }^{72}$.

No obstante, aunque la sociedad española no es proclive a implementarla, cabe destacar que hay reformas penales que otorgan carta de naturaleza a las prácticas de Justicia Restaurativa, por ejemplo, la LO 1/2015, de 30 de marzo, de modificación del Código Penal, se refiere por primera vez a la mediación penal de adultos (si se excluye la mención a la LO 1/2004, de 28 de diciembre, de Medidas de Protección Integral contra la Violencia de Género para prohibirla) ${ }^{73}$ y la Ley 4/2015, de 27 de abril, del Estatuto de la víctima del delito ${ }^{74}$, prevé en su artículo 15 el acceso a los servicios de justicia restaurativa para las víctimas a fin de obtener una adecuada reparación material y moral de los perjuicios derivados del delito, siempre que se cumplan una serie de requisitos, lo que supone reposicionar al afectado en el proceso penal o-que es lo mismo- participe en él de manera más activa.

\section{Herramientas de justicia restaurativa en España y principales controversias}

He referido como herramientas de justicia restaurativa fuera de España la mediación penal, los VOM, los VORP, la mediación comunitaria, la unidad de reunión familiar y los círculos de sentencia; y ellas plantean grandes problemas a objeto de implantarlas acá.

Y por ser el mecanismo de resolución alternativo de conflictos por antonomasia, es de resaltar algunas notas características que conforman en la legislación española el concepto de mediación penal: a) es una modalidad de tutela del ciudadano, el proceso penal, pergeñado en el s. XIX, necesita reformas que incorporen nuevas técnicas para ser más eficaz y la mediación es una si se entiende como procedimiento instrumental y complementario y no como un medio alternativo; b) se funda en la libertad y voluntad de las partes de someterse a ella, lo que denota una gran diferencia con el propio proceso penal; c) es un procedimiento y no un proceso (el primero existe en toda actividad jurídica y es la manera formal en que ella se desarrolla y el proceso atañe a juzgar y hacer ejecutar lo juzgado de manera irrevocable), en la mediación despliega labor un tercero que no actúa heterocompositivamente sino autocompositivamente o intrapartes; d) concurre una intervención tripartita de sujetos y con roles diversos; y e) exige que exista igualdad de poder entre las partes (es difícil que se dé entre víctima y un ofensor pues lo común es que uno de ellos esté en situación de superioridad) ${ }^{75}$.

\footnotetext{
${ }^{72}$ VARONA MARTÍNEZ (2016) p. 112.

73 Al terminar este trabajo -mediados de agosto de 2019- en el derecho interno el único respaldo normativo de la mediación había quedado circunscrito al enjuiciamiento penal de menores, a través de LO 5/2000 reguladora de la responsabilidad penal de los menores y del RD 1774/2004, de 30 de julio, por el que se aprueba su Reglamento de desarrollo.

${ }_{74}^{74}$ Vid. artículos 11 a 18 de la Ley 4/2015, de 27 de abril, del Estatuto de la víctima del delito.

${ }^{75}$ BARONA VILAR (2011) pp. 259-266.
} 
A este tiempo, mediados de agosto de 2019, pese a ser importante la mediación penal dentro de las herramientas de justicia restaurativa, los VOM y VORP cabe estimarlos instaurados con timidez en España porque en la responsabilidad penal de adultos hay un clima de alegalidad y se contraviene el principio de legalidad, se está en un limbo legal $^{76}$, porque las referencias a la mediación a la mediación penal son escuetas, por ejemplo, el artículo 84.1.1 a del Código penal dispone que dicha mediación posibilita suspender la ejecución de la pena pero el proceso para alcanzar el correspondiente acuerdo no lo prevé la Ley de Enjuiciamiento Criminal ni algún otro cuerpo legal, y similar pasa con el ya citado artículo 15 del Estatuto de la víctima del delito pues alude a los servicios de justicia restaurativa y tampoco existe ley que desarrolle cómo llevar a cabo estos procedimientos.

Los menores infractores son una excepción a lo anterior ya que la LO 5/2000, de 12 de enero, y que regula su responsabilidad criminal, contempla expresamente cómo realizar la mediación penal respecto de ellos, en concreto, establece el artículo 19 que el Juez puede sobreseer el caso, a instancia del Ministerio Fiscal, si contraventor se concilia con la víctima o se compromete a repararle el daño ocasionado ejecutando determinados actos o actuaciones que supongan dicha reparación, actos supervisados por un equipo técnico de mediación. Eso sí, la mediación se considera una técnica para llegar a una conciliación o reparación, un resultado jurídico, y solamente se permite para delitos menos graves.

Interesante fue el abandonado proyecto de Código procesal pues regulaba este modelo restaurativo en el Título IV (artículos 143 a 146) como consecuencia de la Decisión Marco del Consejo de la Unión Europea de 15 de marzo de 2001 (2001/220/JAI), relativa al Estatuto de la Víctima sustituida por la Directiva 2012/29/UE del Parlamento Europeo y del Consejo de 25 de octubre. Y ciertamente, en el proyecto la mediación penal perseguía utilizar, siempre voluntariamente, un mecanismo de solución del conflicto entre infractor y víctima que satisfaga las expectativas de ella de obtener una explicación del hecho, la petición de perdón y una pronta reparación (o, que es igual, instaurar en España las VOM o VORP). Para el victimario la mediación sólo tendría las consecuencias favorables procesales o materiales que del acuerdo se derivasen, además se pretendía que el procedimiento de mediación penal fuese complementario y no alternativo al proceso penal.

La mediación comunitaria, que supone una mayor identificación con el proceso y motivación para participar en él, y cual sucede con los VOM y VOPR, colisiona con el principio legalidad y por ende en el ordenamiento español es impracticable, otro tanto ocurre con la unidad de reunión familiar -otra de las herramientas de justicia restaurativa- pues también choca con el antedicho principio.

Por último, entiendo que implementar los círculos de sentencia en el ordenamiento jurídico español es imposible porque en el sistema procesal penal se garantiza que el magistrado sea imparcial ${ }^{77}$, que falle ajeno a motivos subjetivos -pueden nacer de una relación con las partes del proceso- u objetivos ${ }^{78}$-pueden surgir por contacto con el objeto del proceso-, situación que no encaja en España ya que en los círculos el Juez,

\footnotetext{
${ }^{76}$ Vid. MARTÍN DIZ (2010) pp. 302-306.

${ }^{77}$ Vid. García LóPEZ-CORCHADO (2006) pp. 14-22.

78 Sentencia del Tribunal Constitucional, núm. 133/2014, de 22 de julio. Recurso de amparo núm. 3930/2012. Ponente: Juan Antonio Xiol Ríos.
} 


\section{AYLLÓN GARCÍA, Jesús Daniel (2019): "La Justicia Restaurativa en España y en otros ordenamientos jurídicos", Ars Boni et Aequi, Año 15, N², pp. 9-29.}

quien participa en el procedimiento con un papel distinto al de su cargo y es parte en todas sus etapas, retoma su rol inicial una vez alcanzado el consenso de actuación frente al acusado y se compromete a imponer la sentencia que el círculo recomendó ${ }^{79}$.

Por tanto, existen dificultades para instaurar las herramientas de justicia restaurativa en España y todas giran, principalmente, en torno al principio de legalidad penal.

\section{Herramientas de justicia restaurativa y principio de legalidad español}

He consignado que la incorporación de la mediación penal en España ha sido tímida, y ello, opino, también se debe a que esta herramienta, de aplicarse entre adultos, choca frontalmente con el principio de legalidad en el estado actual -mediados de agosto de 2019- del ordenamiento jurídico.

El ius puniendi, por el principio de legalidad en su dimensión de garantía jurisdiccional, lo ejerce exclusivamente el Estado dentro de un proceso penal ${ }^{80} \mathrm{y}$, siendo así, que el ofendido y el agresor puedan pactar o acordar la persecución y castigo en materia criminal, a mi entender, no se condice con dicho principio ${ }^{81}$ constituyéndose en tope al avance de la mediación penal en el sistema jurídico español a menos que se instaure con mayor fuerza el principio de oportunidad ${ }^{82}$ o module el de legalidad.

En lo que concierne a las unidades de reunión familiares, tipo de herramienta restaurativa con intervención del ofendido y el victimario e incluso la familia extendida, precisamente por ser ius puniendi potestad exclusiva del Estado en España, las partes en el proceso, y menos todavía los aludidos familiares, no podrían decidir, se opone a ello el principio de legalidad penal, sobre quién participará en ese procedimiento para solventar las consecuencias del hecho delictivo.

En España para la mediación penal evidentemente es obstáculo el principio de legalidad por sus garantías criminal, que exige que el delito se halle determinado por la ley, penal, que implica prohibición de imponer una pena más grave o distinta a la legal (con la mediación penal víctima y victimario podrían solucionar el conflicto con una sanción no establecida en la ley), jurisdiccional, que exige que en un procedimiento legalmente tramitado una sentencia determine la existencia del delito y la pena que por él se impone (con la mediación penal las partes podrían acordar se imponga una pena o conducta concreta y no el juez por medio de sentencia), y de ejecución, que supone ejecutar la pena conforme a la regulación que establece la ley (en la mediación penal la ejecución depende de cumplir voluntariamente el acuerdo) ${ }^{83}$.

No debe abandonarse la lucha por instaurar herramientas restaurativas en España porque, como señala DE LA CUESTA AGUADO ${ }^{84}$, en un sistema penal garantista la implementación de la Justicia Reparadora supondría la recuperación de la víctima y los

\footnotetext{
${ }^{79}$ MERINO ORTIZ y RoMERA ANTÓN (1998) p. 294.

${ }^{80}$ Vid. PRIETO SANCHÍS (2011) pp. 99-112.

${ }^{81}$ MARTín Diz (2010) pp. 308-311.

${ }^{82}$ Vid. COLOMER HERNÁNDEZ (2012) pp. 456-462.

${ }^{83}$ Para más detalle de las garantías del principio de legalidad vid. MIR PUIG (2003) pp. 125-132.

${ }^{84}$ De La Cuesta Aguado (2012) p. 143.
} 
fines victimológicos como propios del Derecho Penal, reposicionar a aquélla en el Derecho y proceso penal.

\section{Líneas básicas para una propuesta de regulación de la mediación penal en España}

Permitida para menores que delinquen la mediación penal, modulándose el principio de legalidad para dar cabida al principio de oportunidad permitiéndose intervenir un mediador para resolver ciertos conflictos penales, sobre todo los que tienen que ver con la reparación del daño (material y moral) causado a la víctima, y uso excepcional de la mediación penal fundado en la especial protección que los menores merecen, el problema para instaurar en España la mediación penal en adultos como medio alternativo de resolución de conflictos radica en determinar si existe un interés que sea superior a todas las garantías del principio de legalidad.

Indiscutiblemente no puede aplicarse a todos las infracciones penales una herramienta restaurativa $^{85}$, desde ya, atendido que una igualdad relativa es la base de toda mediación, a aquellas en las que exista una desigualdad insalvable de posiciones entre las partes y en las que una está en situación de superioridad respecto de la otra, lo que excluye de la justicia restaurativa los delitos relacionados con la violencia de género o doméstica y con las agresiones sexuales.

Por el contrario, deduzco que la mediación penal podría emplearse respecto de delitos perseguibles a instancia de parte ( $v . g r$., injuria y calumnia) y en los que el perdón es eficaz para extinguir la acción penal o la pena impuesta, y en estos casos, tras las sesiones de mediación, se trasladaría el acuerdo al Juez para que lo homologue ajustándolo a la ley porque -aunque a objeto de sanción debe instar el ofendido o su representante- es el titular del ius puniendi. Si las partes acordaran solucionar el conflicto fuera de Tribunales habría una renuncia a la acción penal y no se vulneraría el principio de legalidad porque el ilícito no lo conoce la justicia y, por lo mismo, no se aplica ley penal, tomando la mediación penal simplemente la forma de una herramienta óptima para restaurar la paz entre víctima y victimario.

Es menester que el legislador español deje de lado los llamados a responder al delito con penas privativas de libertad y, estimado que rige el principio de intervención mínima del derecho penal ${ }^{86}$, se decante por instaurar la Justicia Restaurativa.

\section{CONCLUSIONES}

A esta época, mediados de agosto de 2019, en el ordenamiento jurídico español es estimable no tener cabida la Justicia Restaurativa, cuyas principales herramientas son la mediación penal, los círculos de sentencia y las conferencias restaurativas, pues el ius puniendi, concebido como potestad de crear y aplicar las normas penales, está en manos del Estado y no de los particulares, quienes vulnerarían el principio de legalidad penal consagrado en el artículo $25 \mathrm{CE}$ si hicieran uso de ese poder.

La mediación penal y otras herramientas de Justicia Restaurativa y en cuanto pueden colisionar con el principio de legalidad no podrán ser manejadas como un medio alternativo de resolución de conflictos en el ordenamiento jurídico español, más todavía

\footnotetext{
${ }^{85}$ GÓMEZ BERMÚDEZ y COCO GUTIÉRREZ (2012) pp. 15-16.

${ }^{86}$ MARTOS NÚÑEZ (1987) p. 100.
} 
que las soluciones que proponen no se ajustan a las cuatro garantías que conforman dicho principio ni a los tres monopolios que lo caracterizan.

No es viable la mediación penal y cualquier otra herramienta de Justicia Restaurativa como mecanismo alternativo para resolver conflictos penales pero sí como un medio complementario que sirve para impulsar el papel de la víctima en el proceso penal dándole en él un mayor empoderamiento y posibilitándole le resarzan o reparen los menoscabos (materiales y morales) sufridos a consecuencia del delito.

Todos los mecanismos o herramientas restaurativas pivotan, en primer lugar, en torno a la víctima para conseguir sea resarcida, sobre todo moralmente, y se toma en consideración al victimario y, de ser necesario, a la comunidad, por lo que la Justicia Restaurativa jugaría un importante papel en reposicionar a la víctima dentro del proceso penal devolviéndole una parte significativa de la disponibilidad sobre el mismo y las eventuales soluciones.

En otros países, de sistema de Civil Law y de Common Law, se han implementado distintas herramientas de Justicia Restaurativa y con efectos beneficiosos tanto para la víctima como para el ofensor e incluso para la comunidad, en España no hay motivo para no implantar la Justicia Restaurativa y en particular la mediación penal ya que se contempla órdenes como el civil y mercantil y ha tenido resultados óptimos, y de ocurrir ciertamente, modulando o suavizando el modelo de Justicia Retributiva imperante y ciertamente excluyendo los delitos en los que exista una desigualdad patente entre las partes.

\section{BIBLIOGRAFÍA CITADA}

AlmiRAll Serra Aida et al. (2011): "La mediación penal juvenil y comunitaria: una alianza necesaria”, Mediaciones Sociales, № 9, II Semestre, pp. 165-185.

BARONA VILAR, Silvia (1999): Solución extrajudicial de conflictos. Alternative dispute resolution (adr) y derecho procesal (Valencia, Tirant lo Blanch).

, (2011): Mediación Penal. Fundamento, fines y régimen jurídico (Valencia, Tirant lo Blanch).

Carbonell Mateu, Juan Carlos (1995), Derecho Penal: concepto y principios constitucionales (Valencia, Tirant lo Blanch).

CHOYA ForÉs, Nastia (2015): Justicia restaurativas: nuevas perspectivas en mediación. $2014 \quad$ - 2015, pp. 23-24. Disponible en http://www.pensamientopenal.com.ar/system/files/2015/07/doctrina41593.pdf, fecha de consulta: 4 de mayo de 2019.

Christie, Nils (1992): "Conflicts and Property", British Journal of criminology, vol. $17, \quad \mathrm{~N}^{\circ} \quad 1, \quad \mathrm{pp} . \quad 1-15 . \quad$ Disponible en: https://criminologiacabana.files.wordpress.com/2015/10/nils-christie-conflictsas-property.pdf, fecha de consulta: 2 de abril de 2019. 
COLOMER HeRnÁNDEZ, Ignacio (2012): “Mediación penal y sustitución del acusador particular: hacia un nuevo paradigma en la posición de la víctima en el proceso penal", en Vv.Aa. Garciandía GonZÁlez, Pedro María y Soleto MuÑoz, Helena (Dirs.), OubiÑa BARBolla, Sabela (Coord.), Sobre mediación penal (Posibilidades y Límites en un Entorno de Reforma del Proceso Penal Español) (Navarra, Thomson Reuters-Aranzadi), pp. 445-469.

De La Cuesta Aguado, Paz M. (2012): "Fines de la pena y justicia reparadora", en Vv.Aa. Garciandía GonZÁlez, Pedro María y Soleto Muñoz, Helena (Dirs.), OubiÑa BARBolla, Sabela (Coord.), Sobre mediación penal (Posibilidades y Limites en un Entorno de Reforma del Proceso Penal Español) (Navarra, Thomson Reuters-Aranzadi), pp. 127-146.

Domingo De La Fuente, Virginia (2008): "Justicia Restaurativa y Mediación Penal", Revista de Derecho Penal, № 23, pp. 33-68.

, (2012): "Herramientas para la aplicación de la justicia restaurativa: cómo introducir otras prácticas restaurativas además de la mediación penal en España”, Criminología y Justicia, $\mathrm{N}^{\circ}$ 4, pp. 105-114. Disponible en: https://dialnet.unirioja.es/descarga/articulo/4063116.pdf, fecha de consulta: 2 de mayo de 2019.

FERreirós MArCos, Carlos Eloy et al. (2011): "La emergencia de los modelos de mediación en el derecho penal de menores", en VV.AA. La Mediación en el Derecho Penal de Menores (Madrid, Dykinson), pp. 78-79.

GARCÍA FERnÁnDEZ, María Auxiliadora (2014): "La mediación penal y el nuevo modelo de justicia restaurativa", Revista Internacional de Doctrina $y$ Jurisprudencia, $\mathrm{N}^{\circ}$ 7, pp. 1-30. Disponible en: https://docplayer.es/6148600-Lamediacion-penal-y-el-nuevo-modelo-de-justicia-restaurativa.html, fecha de consulta: 5 de mayo de 2019.

GARCÍA LÓPEZ-CORCHADO, Enrique (2006): "Derecho al juez imparcial", La Toga, $\mathrm{N}^{\circ} 161$, pp. 18-24.

GÓMEZ BermúdeZ, Montserrat y COCO GuTIÉRreZ, Susana (2012): "Justicia restaurativa: "Mediación en el ámbito penal"", Revista de Mediación, Año 6, $\mathrm{N}^{\circ}$ 11, pp. 14-19. Disponible en: https://revistademediacion.com/wpcontent/uploads/2013/08/Revista-Mediacion-11-03.pdf, fecha de consulta: 10 de agosto de 2019.

Hombrado TRENADO, Jaume (2015): Justicia restaurativa: El papel del Criminólogo en el ámbito de la mediación penal en justicia juvenil (Barcelona, Universitat de Barcelona). Disponible en: http://diposit.ub.edu/dspace/bitstream/2445/95820/1/TFG_Jaume\%20Hombrado. pdf, fecha de consulta: 20 de abril de 2019.

LANGON CUÑARRO, Miguel (2000): "La vergüenza reintegradora de John Braithwaite", Revista de la Facultad de Derecho, N $^{\circ}$ 18, pp. 63-68. 
AyLlón GARCíA, Jesús Daniel (2019): “La Justicia Restaurativa en España y en otros ordenamientos jurídicos”, Ars Boni et Aequi, Año 15, №2, pp. 9-29.

LÓPEZ RuANOVA, Tania María (2010): "Mediación penal en menores. Delincuencia juvenil", en Souto GalváN, Esther (Dir.), La mediación. Un instrumento de conciliación (Madrid, Dykinson), pp. 251-285.

Marshall, Tony F (1999): Restorative Justice: An overview. Disponible en: http://fbga.redguitars.co.uk/restorativeJusticeAnOverview.pdf, fecha de consulta: 20 de marzo de 2019.

MARTín DIZ, Fernando (2010): La mediación: sistema complementario de Administración de Justicia (Madrid, Consejo General del Poder Judicial, Centro de Documentación Judicial).

MARTOS NúÑEZ, Juan Antonio (1987): "El principio de intervención penal mínima", Anuario de Derecho Penal y Ciencias Penales, T. 40, fasc. $\quad 1$, pp. 99-134. Disponible en: https://www.boe.es/publicaciones/anuarios_derecho/abrir_pdf.php?id=ANU-P1987-10009900134, fecha de consulta: 20 de julio de 2019.

McCOLD, Paul (2013): "La historia reciente de la justicias restaurativa. Mediación, círculos y conferencias", Delito y Sociedad, N³6, Vol. 2, pp. 9-44. Disponible en: https://bibliotecavirtual.unl.edu.ar/publicaciones/index.php/DelitoYSociedad/arti cle/view/5529/8264, fecha de consulta: 4 de abril de 2019.

Merino Ortiz, Cristina y Romera Antón, Carlos (1998): "Conferencias de grupos familiares y sentencias circulares: dos formas ancestrales de resolución de conflictos dentro del paradigma restaurativo", Eguzkilore, No 12, pp. 285-303.

MIR PUIG, Santiago (2003): Introducción a las bases del Derecho Penal (Reimpresión de $2^{a}$ ed. 2002, Montevideo - Buenos Aires, B de f).

PENNELl, Joan y BURFORD, Gale (1996): “Attending to context: family group decision making in Canada", en Hudson, Joe y MoRRIS, Allison (Eds.), Family Group Conferences: perspectives on policy and practice (Nueva York, Monsey, Editorial Criminal Justice Press), pp. 206-220.

PÉREZ SANZBERRO, Guadalupe (1999): Reparación y conciliación en el sistema penal ¿Apertura a una nueva vía? (Granada, Editorial Comares).

PRANIS, Kay (2012): Manual para facilitadores de Círculos (Trad. Sara Castillo, San José de Costa Rica, Conamaj). Disponible en: https://www.conamaj.go.cr/images/libros/pdf/011.pdf, fecha de consulta: 15 de mayo de 2019.

PRIETO SANCHÍs, Luis (2011): Garantismo y derecho penal (Madrid, Iustel). 
Ríos MARTín, Julián Carlos et al. (2008): La mediación penal y penitenciaria. Experiencias de diálogo en el sistema penal para la reducción de la violencia y el sufrimiento humano (Madrid, Editorial Colex).

Ríos Martín, Julián Carlos y Olalde Altarejos, Alberto José (2011): "Justicia Restaurativa y mediación. Postulados para el abordaje de su concepto y finalidad", Revista de Mediación, Año 4, N 8, pp. 10-19. Disponible en https://revistademediacion.com/articulos/justicia-restaurativa-y-mediacionpostulados-para-el-abordaje-de-su-concepto-y-finalidad/, fecha de consulta: 20 de mayo de 2019.

ROMERA ANTón, Carlos (2007): "Conferencias comunitarias y justicia restaurativa", Estudios de Derecho Judicial (La mediación civil y penal. Un año de experiencia), $\mathrm{N}^{\circ} 136$, pp. 189-206.

SEgovia Bernabé, José Luis (2010): "Mediación penal comunitaria y justicia restaurativa. Perspectiva ética y jurídica", FAMILIA, $\mathrm{N}^{\circ} 41, \mathrm{pp}$. $35-65$. Disponible en https://summa.upsa.es/high.raw $? \mathrm{id}=0000030579 \&$ name $=00000001$.original.pdf, fecha de consulta: 18 de mayo de 2019.

SOlETO MuÑOZ, Helena (2013): "Aportaciones internacionales al desarrollo de la Justicia Restaurativa en España”, en VV.AA. ECHANO BASALDUA, Juan Ignacio (Dir.), Justicia restaurativa, una justicia para el siglo XXI: potencialidades y retos [Cuadernos penales José María Lidón núm. 9], pp. 77-106. Disponible en: http://www.deusto-publicaciones.es/deusto/pdfs/lidon/lidon09.pdf, fecha de consulta: 18 de mayo de 2019.

TAMARIT Sumalla, Josep María (2012): La justicia restaurativa: Desarrollo y Aplicaciones (Granada, Editorial Comares).

, (2013): "El necesario impulso de la Justicia restaurativa tras la Directiva europea de 2012", Ars Iuris Salmanticensis, vol. 1, pp.139-160. Disponible en: http://revistas.usal.es/index.php/ais/article/view/10310/10740, fecha de consulta: 18 de mayo de 2019.

VARONA MARTÍNEZ, Gema (1998): La mediación reparadora como estrategia de control social. Una perspectiva criminológica (Granada, Editorial Comares).

(2016): "Servicios sociales y justicia restaurativa: el caso del Servicio de Mediación Penal de Barakaldo", Zerbitzuan, № 61, pp. 103-116. Disponible en: http://www.zerbitzuan.net/documentos/zerbitzuan/Zerbitzuan61.pdf, fecha de consulta: 18 de abril de 2019.

WERTH WAINER, Francisca (2005): Sistemas de Justicia Juvenil: la experiencia comparada, Estados Unidos, Canadá y Reino Unido (Santiago de Chile, Fundación Paz Ciudadana). Disponible en https://pazciudadana.cl/biblioteca/documentos/sistemas-de-justicia-juvenil-laexperiencia-comparada-estados-unidos-canada-y-reino-unido/, fecha de consulta: 28 de mayo de 2019. 
AyLlón GARCíA, Jesús Daniel (2019): “La Justicia Restaurativa en España y en otros ordenamientos jurídicos", Ars Boni et Aequi, Año 15, N², pp. 9-29.

ZEHR, Howard (1985): Retributive justice, restorative justice: New Perspectives on Crime and Justice (Occasional Papers of the MCC Canada Victim Offender Ministries Program and the MCC US Office of Criminal Justice, $\mathrm{N}^{\mathrm{o}} 4,16 \mathrm{p}$ ). Disponible en: https://www.academia.edu/1299660/Retributive_justice_restorative_justice_Ne w_perspectives_in_crime_and_justice, fecha de consulta: 15 de mayo de 2019.

ZEHR, Howard y GOHAR, Ali (2005): The little book of restorative justice (Pennsylvania, Good Books). Disponible en: https://www.unicef.org/tdad/littlebookrjpakaf.pdf, fecha de consulta: 7 de mayo de 2019.

\section{NORMAS JURÍDICAS CITADAS}

Real Decreto de 14 de septiembre de 1882, aprobatorio de la Ley de Enjuiciamiento Criminal.

Constitución española de 1978.

Ley Orgánica 5/1995, del Tribunal del Jurado, de 22 de mayo.

Ley Orgánica 10/1995, del Código Penal, de 23 de noviembre.

Ley Orgánica 5/2000, reguladora de la responsabilidad penal de los menores, de 12 de enero.

Ley Orgánica 1/2004, de Medidas de Protección Integral contra la Violencia de Género, de 28 de diciembre.

Ley 4/2015, del Estatuto de la víctima del delito, de 27 de abril.

\section{JURISPRUDENCIA CITADA}

Tribunal Constitucional Español (2014): 22 julio 2014, sentencia núm. 133/2014. Recurso de amparo núm. 3930/2012. Ponente: Juan Antonio Xiol Ríos. Aranzadi RTC 2014/133. 